\title{
Acquiring a new second language contrast: an analysis of the English laryngeal system of first language Dutch speakers
}

\section{Ellen Simon Ghent University}

Received February 2007; revised February 2008; accepted March 2008

This study examines the acquisition of the English laryngeal system by native speakers of (Belgian) Dutch. Both languages have a twoway laryngeal system, but while Dutch contrasts prevoiced with short-lag stops, English has a contrast between short-lag and longlag stops. The primary aim of the article is to test two hypotheses on the acquisition process based on first language acquisition research: (1) native speakers of a voicing language will succeed in producing short-lag stops in the target aspirating language, since short-lag stops occur early in first language acquisition and can be considered unmarked and since one member of the contrast is formed by shortlag stops in both voicing and aspirating languages, and (2) native speakers of a voicing language will succeed in acquiring long-lag stops in the target language, because aspiration is an acoustically salient realization. The analysis is based on an examination of natural speech data (conversations between dyads of informants), combined with the results of a controlled reading task. Both types of data were gathered in Dutch as well as in Eng $_{\text {Dutch }}$ (i.e. the English speech of native speakers of Dutch). The analysis revealed an interesting pattern: while the first language (L1) Dutch speakers were successful in acquiring long-lag aspirated stops (confirming hypothesis 2), they did not acquire English short-lag stops (rejecting hypothesis 1). Instead of the target short-lag stops, the L1 Dutch speakers produced prevoiced stops and frequently transferred regressive voice assimilation with voiced stops as triggers from Dutch into English.

Address for correspondence: Ellen Simon, English Department, Ghent University, Rozier 44, 9000 Ghent, Belgium; email: Ellen.Simon@UGent.be 
Various explanations for this pattern in terms of acoustic salience, perceptual cues and training will be considered.

Keywords: L2 phonology, laryngeal, voicing, VOT, assimilation, Dutch, acoustic salience

\section{Introduction}

The article focuses on the acquisition of the English laryngeal system by native speakers of (Belgian) Dutch and aims to find out to what extent they acquire the English voicing contrast, and which factors shape the acquisition process. It is well known that languages differ in the complexity of their laryngeal stop contrast: whereas some languages have only one laryngeal category (e.g. Hawaiian), others have a two-way contrast (e.g. Spanish), a three-way contrast (e.g. Thai), a four-way contrast (e.g. Hindi) or an even more complex system (e.g. Sindhi).

The two languages studied in this article - Dutch and English - both maintain a two-way contrast in stops. However, the laryngeal systems in these two languages are considerably different. Whereas in English voiceless stops are aspirated in most contexts, they are unaspirated in Dutch. Voiced stops, on the other hand, are usually produced with prevoicing (also called voicing lead) in Dutch (which means that there is vocal-fold vibration before the release phase of the stop), but are often phonetically voiceless in English, at least in word-initial position. English has therefore sometimes been called an 'aspirating language', while Dutch is called a 'voicing language' (Jansen, 2004). Moreover, voiced stops play an important and active role in Dutch, as word-initial voiced stops trigger regressive voicing assimilation in preceding word-final obstruents (e.g. dat boek 'that book': /dat buk/ is realized as [dad buk]). Regressive voice assimilation (henceforth RVA) in the direction of voicedness does not occur in English.

In terms of Voice Onset Time (henceforth VOT), the contrast in Dutch is one between prevoiced stops (i.e. stops with a negative VOT) and shortlag stops, while English has a contrast between short-lag and long-lag stops. Of course VOT is just one phonetic correlate of the laryngeal contrast and in some languages, such as Korean, it is not a good indicator of the contrast between different categories. Ito et al. (2006) discuss the intricate pattern of Japanese loan-word adaptation into Korean. Since Japanese has a two-way contrast (distinguishable by means of VOT), while Korean has a three-way contrast (in which VOT does not suffice to make the contrast 
between tense and lax stops), there is no straightforward correspondence between the laryngeal categories of these two languages. However, both Dutch and English have a two-way laryngeal contrast, which can easily be expressed in terms of VOT. This means that native speakers of Dutch learning English have to neither (1) create an extra category, which they would if they were learning a language with a three-way laryngeal contrast such as Thai, nor (2) lose a category, which would be necessary if they were learning a language with no laryngeal contrast in its stop system, such as Hawaiian (Iverson and Salmons, 2003: 3).

In Best's Perceptual Assimilation Model (commonly abbreviated as PAM; Best, 1994; 1995; Best et al., 2001) this type of correspondence between source and target language -i.e. when the number of categories in a contrast is the same in the source and the target language - is called a 'two-category assimilation'. It is contrasted with a 'single-category assimilation', in which two categories in the target language are associated with only one category in the source language. Escudero (2005), in her 'L2 Linguistic Perception' model states that, although it is easier to learn to perceive a contrast in the second language (L2) if it is already there in the L1 (which she terms a 'SIMILAR scenario'), it still poses a learning task, since the phonetic implementation of the contrast will be language specific. She argues that, in a SIMILAR scenario, learners can reuse their L1 categories but need to shift the boundaries of the L1 perception in the direction of the L2 (Escudero, 2005: $257 \mathrm{ff}$.). The exact nature of the learning task for native speakers of a voicing language such as Dutch who learn an aspirating language such as English in fact depends on which approach one takes to the laryngeal features in voicing and aspirating languages. Two main theories can be distinguished.

According to one theory, the contrastive feature is [voice] in voicing languages, but [spread glottis] in aspirating languages. Voiced stops are then considered to be marked for [voice] in Dutch, but unmarked in English, while voiceless stops are unmarked in Dutch, but marked for [spread glottis] in English (Iverson and Salmons, 1995; 1999; 2003; 2006; Avery and Idsardi, 2001). Evidence for this view has been based on first language acquisition (Kager et al., 2007; Van der Feest, 2007) as well as on historical data (Honeybone, 2005).

A second approach, from a typological perspective, is that all Germanic languages, including Dutch and English, have the same twoway contrast between voiced (specified for [+voice]) and voiceless stops (specified for [-voice]). According to this binary [voice] approach 
the only difference between voicing and aspirating languages lies in the phonetic realization of the contrast. ${ }^{1}$ For arguments in favour of the view that the feature [voice] marks the laryngeal contrast in both voicing and aspirating language, see Kingston and Diehl (1994).

Whichever approach one takes, it is clear that native speakers of Dutch learning English have to shift the boundary between the two categories in Dutch (i.e. the boundary between prevoiced and short-lag stops) in the direction of the English boundary between short-lag and long-lag stops. Previous research on L1 acquisition of two-way voice contrasts has revealed two interesting findings, which are relevant to the present study.

A first important finding from first language acquisition studies is that children acquiring a voicing language as well as children acquiring an aspirating language go through a stage in which they do not make a contrast between the two categories and produce only short-lag stops. Macken and Barton (1979) conducted a longitudinal study with four children acquiring American English and found that in a first stage the children produced all stops in the short-lag VOT region, which was taken to be between $0-20 \mathrm{~ms}$ for labial and alveolar stops and between $0-40 \mathrm{~ms}$ for velars. The same pattern was found by Kager et al. (2007). On the basis of the CLPF (Claartje Levelt and Paula Fikkert) database for Dutch (Fikkert, 1994; Levelt, 1994) and the Nijmegen Database in CHILDES (MacWhinney, 1999), Kager et al. found that children learning Dutch produced devoicing errors (e.g. douche 'shower' and beer 'bear' were produced with unprevoiced stops), and that the single child learning German whose speech was examined produced more deaspirating errors (e.g. Tag 'day' and Turm 'tower' were produced without aspiration). This means that both the Dutch and the German children produced voiceless unaspirated stops, i.e. stops that were neither prevoiced nor aspirated. Kager et al. (2007) note that these results can be interpreted phonetically under an Ease of Articulation analysis: if it is assumed that short-lag, unaspirated stops are easiest to produce (Kager et al., in Van der Feest, 2007: 53), the Dutch- and German-learning children's early productions might be the result of a drive towards these unmarked realizations. ${ }^{2}$

\footnotetext{
${ }^{1}$ Another issue that is subject to debate is whether laryngeal features are unary or binary. For discussions and different views, see for example Lombardi, 1995; 1996; Cho, 1999; Wetzels and Mascaró, 2001.

${ }^{2}$ Vaux and Samuels (2005) argue that the laryngeally unmarked stops frequently produced by children are not necessarily short-lag stops but are realized within a very wide VOT range, i.e. their realization is very variable rather than necessarily within to the short-lag region.
} 
A second finding from $\mathrm{L} 1$ acquisition research is that children learning an aspirating language acquire the voice contrast earlier than children acquiring a voicing language. While children acquiring an aspirating language acquire the contrast between short-lag and long-lag stops around the age of 2;0 (Macken and Barton, 1979; Snow, 1997), children acquiring a voicing language may not learn to produce prevoicing before the age of 3;0 or even later (Kuijpers, 1993; Van der Feest, 2007). This difference in age of acquisition suggests that aspirated stops are relatively easy to acquire compared to prevoiced stops, presumably because of the great acoustic salience of aspiration.

On the basis of these findings from first language acquisition, we can formulate two hypotheses with respect to the acquisition of the laryngeal contrast in an aspirating language by L1 speakers of a voicing language, in this case the acquisition of English by native speakers of Dutch.

- Hypothesis 1: Native speakers of a voicing language will succeed in producing short-lag stops in the target aspirating language. This hypothesis is based on two findings. First, research on L1 acquisition has shown that short-lag stops form the first category, which is acquired by children learning a voicing or an aspirating language and can thus be considered unmarked and easy to acquire in L2 acquisition. Second, both voicing and aspirating languages use short-lag stops as one member of the voice contrast. Since the target short-lag stops are acoustically very close to the short-lag stops in the native language, learners are expected to have no difficulty acquiring the L2 short-lag stops.

- Hypothesis 2: Advanced learners of an aspirating language with a voicing language as their native language will succeed in producing the voiceless stops in the target language with a long-lag VOT. This hypothesis is based on L1 acquisition studies, which have shown that children learning a language with a contrast between short-lag and long-lag stops acquire this contrast earlier than children learning a language that contrasts prevoiced stops with short-lag ones. If long-lag stops are acoustically salient and acquired early in L1 acquisition, advanced L2 learners are expected to acquire the production of long-lag stops in the target language.

If both hypotheses were to be confirmed by the analysis of the laryngeal stop system in the English speech of native speakers of Dutch presented in this article, this would mean that the L1 Dutch speakers succeed in acquiring the English contrast between short-lag and long-lag stops. 
They would equate English short-lag stops with Dutch short-lag stops, because they are acoustically very close to one another and would additionally learn to produce aspiration in voiceless stops, as this is an acoustically salient process. However, there are two other potential learning paths that could be taken by L1 Dutch-speaking learners of English.

One other possibility is that native speakers of Dutch learn that the Dutch short-lag stops $/ \mathrm{p}, \mathrm{t}, \mathrm{k} /$ are realized with a long-lag VOT in English and that Dutch prevoiced $/ \mathrm{b}, \mathrm{d} /$ are not produced with prevoicing in English, but are instead realized in the short-lag region. Under this scenario, native speakers of Dutch would have shifted both voice categories and have completely acquired the English voice contrast.

Finally, Dutch-speaking learners of English may categorize English long-lag stops as Dutch short-lag ones and English short-lag stops as Dutch prevoiced ones. Under this scenario, the learners would in fact fully transfer the Dutch realization of the contrast into English.

The article aims to discover which learning path a group of L1 Dutch learners of English have taken and to test hypotheses (1) and (2) formulated above by examining the production of voiced and voiceless stops in Dutch and Eng ${ }_{\text {Dutch }}$ natural running speech and in a reading task. The remainder of this article looks as follows: Section II describes the methodology by providing information about the informants, the data, and the measurements. Section III presents the results, which are discussed and compared to findings in L1 acquisition research in Section IV. Finally, Section V contains the conclusions and a suggestion for further research.

\section{Methodology}

\section{The informants}

The informants are 16 native speakers of Dutch living in Flanders. At the time of the recordings, they were all second-year students of English at university level. All the informants had taken an English pronunciation class in the year preceding the recordings, which included sessions in which the informants individually listened to pronunciation tapes, recorded their own speech and listened back to what they had recorded. Although there are of course differences between the informants as far as their English pronunciation is concerned, all informants have attained the level at which they can express themselves fluently in the foreign language and their pronunciation can be called advanced. 
Ten native speakers of (British or Irish) English also performed a reading task - compare (2) - and functioned as a control group.

\section{The data: natural speech and a reading task}

In order to investigate the acquisition of the English laryngeal contrast by native speakers of Dutch, a spoken corpus with comparable data in

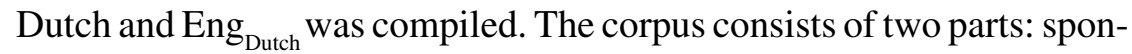
taneous conversations between dyads of informants and a word-reading task. For the conversations, eight dyads of informants were asked to talk to each other for about 30 to 45 minutes about any subject they liked. For each dyad two conversations were recorded: the first conversation was in Dutch and the second one in English. This order was always respected, as it allowed the informants to get to know one another a little before the second recording session took place, so that the threshold to speak English to each other was lowered. No third person was present in the room during the recordings, so as to elicit maximally natural speech. (It is possible that the subjects' pronunciation would have been slightly different if the English conversations had taken place between a Dutchspeaking learner and an L1 English speaker. However, this would have decreased the casualness of the conversations and, since the informants knew that they were being recorded, they presumably attempted to sound as English as possible.)

Ten out of the 16 informants who participated in the spontaneous conversations and 10 native speakers of English also performed a reading task. They were asked to read aloud 37 Dutch and 38 English words in isolation. The words appeared one at a time (every 3 seconds) on a computer screen and were mainly used to examine the production of aspiration, sonorant consonant devoicing after voiceless stops and prevoicing. All the words from the reading task can be found in Appendix 1.

\section{The transcriptions, measurements and coding system}

Fifteen minutes of each conversation were orthographically transcribed in Praat (Boersma and Weenink, 2008). All single word-initial voiceless stops occurring in a stressed syllable in the conversations and in the reading task were measured for VOT. Tokens of which the VOT was hard to measure, because they occurred in overlapping speech or in a stretch of speech which was, for instance, mumbled or produced with laughter were rejected. RVA was coded on the basis of auditory 
judgements by the author and part of the data was coded by a second, phonetically trained transcriber. Because the interrater agreement, which was calculated on the basis of the coefficient kappa (see Eggen and Sanders, 1993), proved to be very high in this sample, it was decided that the auditory judgments on the presence or absence of RVA were reliable.

All single word-initial voiceless and voiced stops (as in pie and boy), as well as all word-initial voiceless stops followed by a sonorant consonant (as in play) in the reading task were acoustically analysed for VOT.

\section{Results}

This section discusses four points on which the voice realizations in Dutch and English differ: (1) prevoicing, (2) RVA in coda obstruent + onset voiced stop clusters, (3) aspiration, and (4) sonorant consonant devoicing after onset voiceless stops. Phenomena (1), (3) and (4) focus on the realization of word-initial stops and will be phonetically analysed. The second process, RVA, is a phonological rule which occurs both across and within word-boundaries and affects coda obstruents followed by onset voiced stops. Whereas the analyses of prevoicing and RVA shed light on the realization of voiced stops in Eng $_{\text {Dutch }}$ (discussed in 1 below), acoustic measurements of aspiration and sonorant consonant devoicing after initial stops provide information about the realization of voiceless stops (discussed in 2).

\section{Voiced stops}

a Prevoicing: Prevoicing refers to the presence of vocal fold vibration before the release phase of a stop. Producing vocal fold vibration in stops is difficult from an aerodynamic point of view, as the closing articulators and the raised soft palate lead to a rapid increase in intraoral air pressure, which inhibits the vocal folds to vibrate. Both active expansion (e.g. lowering the larynx) and passive expansion (e.g. allowing the soft, compliant tissue of the lips, cheeks and soft palate to expand) can be used to enlarge the oral cavity and thus to delay the rise in supraglottal air pressure (Kingston, 2004: 231-234).

In Dutch, voiced stops are generally prevoiced (Lisker and Abramson, 1964; Van Dommelen, 1983; Van Alphen, 2004). Van Alphen (2004) conducted an experiment with 10 native speakers of Dutch living in the Netherlands, who were asked to read a list of Dutch words and nonce 
words starting with a voiced stop. ${ }^{3}$ She found that $85.5 \%$ of the initial stops followed by a vowel (in words like boot 'boat', deur 'door' and duin 'dune') were produced with prevoicing.

In English, on the other hand, onset voiced stops usually lack prevoicing and are thus phonetically voiceless. However, a number of studies have shown that the situation in English is not unambiguous and that there can be considerable differences between speakers. Lisker and Abramson (1964) analysed words read aloud by four native speakers of American English and found that, whereas three speakers never or hardly ever produced a token with prevoicing, one speaker consistently produced prevoicing (in 41 out of 42 tokens). Flege's (1982) research on the realization of the words pay and bay by 10 native speakers of American English revealed that 117 out of 120 tokens of bay were produced with prevoicing. These results stand in sharp contrast to those found by Docherty (1992) for five native speakers of Southern British English, who produced the overwhelming majority of tokens (346 out of 371, i.e. 93\%) without prevoicing. One common finding in these three investigations was, however, that speakers did not randomly produce prevoiced and unprevoiced stops, but that each speaker more or less consistently produced or lacked prevoicing in onset voiced stops.

The analysis of prevoicing in the present study was based on a wordreading task, which contained 20 Dutch and 20 English words with a voiced stop in the onset, so that in total 200 Dutch tokens (20 tokens produced by 10 informants) and 200 English tokens were analysed for presence or absence of prevoicing. For both languages, half of the tokens started with bilabial $/ \mathrm{b} /$, the other half with alveolar $/ \mathrm{d} / \mathrm{.}^{4}$ Examples are bal 'ball', boom 'tree', deel 'part' and doos 'box' for Dutch and boy, bean, date and dot for English. The production of prevoicing was analysed in Praat (Boersma and Weenink, 2008) on the basis of waveforms and spectrograms. The analysis revealed that the overall majority of Dutch word-initial voiceless stops, namely 186 out of 200 (i.e. 93\%), were produced with prevoicing. Moreover, seven of the 14 tokens that lacked prevoicing were produced by the same

\footnotetext{
${ }^{3}$ The list also contained a substantial number of fillers, so as not to attract the reader's attention to the initial voiced stop. The distinction between real Dutch words and nonce words proved to have no effect on the production of prevoicing.

${ }^{4}$ Since more laryngeal expansion is possible in bilabial $/ \mathrm{b} /$ than in alveolar $/ \mathrm{d} /$, the place of articulation of the onset stop was controlled. Ideally, however, the height of the following vowel should also have been taken into account.
} 
informant. The lower frequency of prevoicing in Van Alphen's (2004) study, in which $85.5 \%$ of the onset voiced stops followed by a vowel were produced with prevoicing, might be due to the fact that, whereas the informants in the present study are native speakers of Belgian Dutch, those in Van Alphen's study are native speakers of Dutch in the Netherlands, whose overall pronunciation is considerably different. The average prevoicing duration, on the other hand, proved to be very similar in both studies: $117.5 \mathrm{~ms}$ in Van Alphen's study and $115 \mathrm{~ms}$ in the present study.

The 10 native speakers of English who participated in the reading task produced $72.5 \%$ of the English voiced stops (i.e. 145/200) without prevoicing, and the majority of tokens with prevoicing (i.e. 30/55) were produced by only two speakers. These results are very different from those of the Dutch-speaking informants, who produced only 15 out of the 200 English tokens without prevoicing. Whereas the English-speaking informants thus produced prevoicing in only $27.5 \%$ of the tokens, the Dutch-speaking informants prevoiced stops as frequently in English (92.5\% of the tokens) as in Dutch (93\% of the tokens).

$b$ RVA: In Dutch, but not in English, there is a phonological process through which a word-final voiceless obstruent is realized as voiced when followed by an onset voiced stop (see, for example, Trommelen and Zonneveld, 1979: 106; Collier and Droste, 1983: 35; Slis, 1985: 122; Booij, 1995: 59). Examples of RVA across word boundaries are the following:

Dutch:

dik boek /dik buk/ $\quad \rightarrow$ [dig buk] 'thick book'

groot bed /yro:t bed/ $\quad \rightarrow$ [yro:d bet] 'large bed'

In English, there is no process of RVA, as is illustrated in the following phrases:

English:

\begin{tabular}{|c|c|c|}
\hline $\begin{array}{l}\text { nice boy /nais boI/ } \\
\text { get better / get betə/ }\end{array}$ & $\begin{array}{l}\rightarrow \text { [nars bəI }] \\
\rightarrow \text { get 'betə] }\end{array}$ & $\begin{array}{l}\text { and not } *[\text { narz b } ~ \\
\text { and not }]\end{array}$ \\
\hline
\end{tabular}

In the Dutch and English conversations, respectively 334 and 139 tokens consisting of a word-final voiceless obstruent followed by a word-initial voiced stop (/b/ or /d/ in Dutch and /b/, /d/ or /g/ in English) were coded for presence or absence of RVA. The results are presented in Table 1. 
Table 1 RVA in voiceless obstruent + voiced stop clusters

\begin{tabular}{ll}
\hline Dutch & Eng $_{\text {Dutch }}$ \\
\hline $306 / 334(92 \%)$ & $82 / 139(59 \%)$ \\
\hline
\end{tabular}

In the Dutch conversations, $92 \%$ of all word-final obstruents that were followed by a word-initial voiced stop were realized as voiced as the result of RVA. Whereas RVA to voicedness does not normally occur in L1 English, the informants produced it in 59\% of the tokens. The following examples taken from the corpus illustrate the production of RVA in Dutch and Eng ${ }_{\text {Dutch }}$ :

Dutch:

groep Duitse (toeristen): /yrup 'dœytsə/ $\rightarrow$ [yrub 'dœytsə] 'group of German (tourists)'

Engels doen: /'eyəls du:n/ $\rightarrow$ ['enəlz du:n] 'taking (lit. doing) English'

Eng $_{\text {Dutch }}$ :

bit boring /bit 'bo:rıy/ $\rightarrow$ *[bId 'bo:rıy]

this girlfriend /ðIs 'g3:lfrend/ $\rightarrow$ *[ðIz 'gs:lfrend]

Since RVA does not normally occur in English, the high frequency with which it occurred in Eng ${ }_{\text {Dutch }}$ indicates that the informants have transferred the phonological process of RVA from their mother tongue into the foreign language. This is in line with research by Kim and Zsiga (2002), who examined the acquisition of different phonological processes in the English speech of native speakers of Korean and found that both beginning and advanced learners frequently transferred the process of intervocalic voicing assimilation from Korean into English. Darcy (2006), on the other hand, investigated the perceptual acquisition of English by native speakers of French and found that the advanced learners in her study learnt that the phonological process of voice assimilation is absent in English, as their performance in word recognition tasks did not differ from that of native speakers. The fact that the native speakers of Dutch in the present study produced RVA in a lower percentage of tokens in the English conversations than in the Dutch conversations might thus point to the fact that some informants have learnt that this phonological process is absent in English. Another explanation for the lower percentage in English might be that the informants speak more slowly in the foreign language than in their 
mother tongue. Since it has been shown that the extent to which voice assimilations occur decreases as speech rate decreases (Slis, 1985) and the informants spoke less fluently and therefore slightly more slowly in the Eng $g_{\text {Dutch }}$ than in the Dutch conversations, the lower occurrence of RVA in the Eng ${ }_{\text {Dutch }}$ conversations in comparison to the Dutch ones might be a result of this slower speech rate.

\section{Voiceless stops}

a Aspiration: Voiceless stops are unaspirated in Dutch, but are (or, in some contexts, can be) produced with aspiration in English (except in the context where the stop is preceded by /s/, as in 'spy' and 'sky'). Because aspiration is heaviest in the onset of a stressed syllable (see, for example, Spencer, 1996: 206-12), the analysis of aspiration in Eng $_{\text {Dutch }}$ deals only with those voiceless stops occurring initially in a stressed syllable. In order to investigate to what extent the Dutchspeaking informants have learnt to aspirate English stops, the VOTs of all word-initial voiceless stops occurring in a stressed syllable and followed by a vowel in the spontaneous conversations (a total of 525 stops) were measured. In 16 tokens the production of the stop was followed by a period of heavy friction (e.g. two was realized as [ $\mathrm{t}^{\mathrm{s}} \mathrm{u}$ :] instead of as [ $\left.\left.{ }^{\mathrm{t}} \mathrm{u}:\right]\right)$. These tokens are left out of the discussion. ${ }^{5}$ The measurements revealed that the average VOT for all 16 informants together was $48 \mathrm{~ms}$. As most studies on VOT in English are based on laboratory speech (e.g. Lisker and Abramson, 1964; Klatt, 1975; Docherty, 1992), this value cannot be readily compared to a value in L1 English.

The word-reading task contained three Dutch and three English words starting with /p, t, k/, namely Dutch paar 'pair', test 'test' and kaak 'cheek' and English pie, take and cake. The average VOT for the English words read by the Dutch-speaking informants proved to be $80 \mathrm{~ms}$, which is considerably higher than the average VOT produced in the Dutch words, which was $21 \mathrm{~ms}$ (similar results for Dutch were found by: Lisker and Abramson, 1964; Flege and Eeftink, 1987). The average VOT value of $80 \mathrm{~ms}$ in the English words is higher than the average VOT found by Docherty (1992) in the speech of five native

${ }^{5}$ The production of frication instead of aspiration might be the result of influence from certain varieties of English (fricated /t/s are, for instance, characteristic of Australian English, see Jones and McDougall, 2005), but they may also be the result of the learner's failed attempt to produce aspiration. 
speakers of British English (63 ms) and by Klatt (1975) in the speech of three native speakers of American English (61 ms). In both Docherty's (1992) and Klatt's (1975) study, however, the words were embedded in carrier phrases, which might explain the lower values. The results are in line with a study by Flege and Eeftink (1987), in which nearly all Dutch-speaking learners of English produced longer VOTs in English than in Dutch words.

Figure 1 shows the average VOT produced by each native speaker of Dutch in the Dutch and English isolated words and in the English conversations. It shows that for most informants the average VOT is lowest in the Dutch words, higher in the English conversations and highest in the English words. Earlier studies (e.g. Kessinger and Blumstein, 1998) have shown that VOT decreases as speech rate increases. Because the speech rate in the conversations was much higher than in the reading task, lower values in the spontaneous conversations as opposed to the reading task were thus expected. However, the difference between the VOTs produced by the informants in the conversations and in the reading task is too large to be ascribed solely to a difference in speech rate. Presumably, some informants did not manage to produce aspiration when they paid minimal attention to their pronunciation, i.e. in the spontaneous conversations. The figure also shows that the differences between informants are much lower in the Dutch words than in the English words and conversations.

The 10 native speakers who acted as a control group produced an average VOT of $76 \mathrm{~ms}$, which is slightly lower than the average VOT

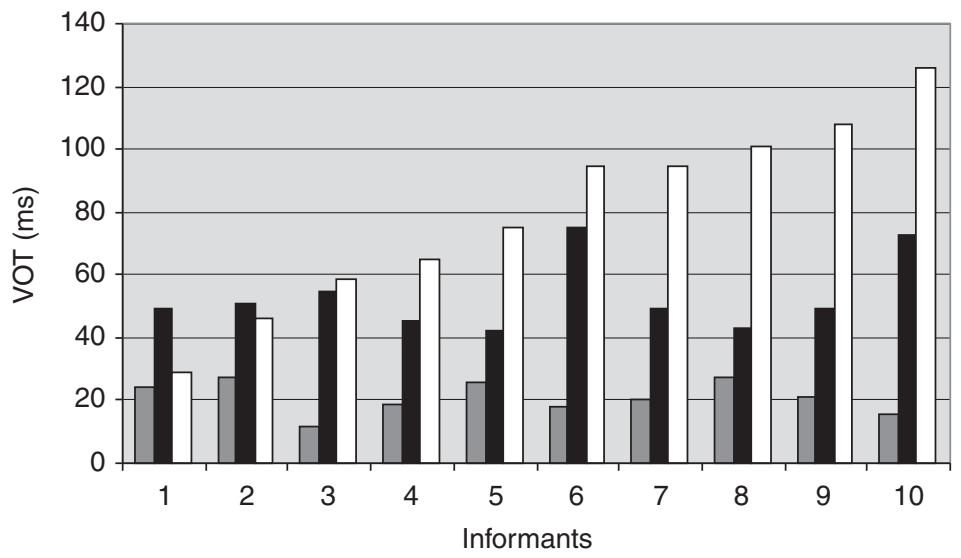

Figure 1 Average VOT per informant in the Dutch words (grey bar), the English conversations (black bar) and the English words (white bar) 
produced in the English words by the L1 Dutch speakers $(80 \mathrm{~ms})$. The interspeaker differences were, however, much lower for the L1 English speakers than for the L1 Dutch speakers.

b Sonorant consonant devoicing: In English, sonorant consonants are devoiced when following onset voiceless stops, as in crop [krop] and twice [twaIs]. The process of sonorant consonant devoicing is related to the process of aspiration: if an onset voiceless stop is followed by a vowel, aspiration will be produced; if it is followed by a sonorant consonant, the time the glottis needs to close leads to (partial) devoicing of the following sonorant (see, for example, Cruttenden, 2001: 151). Both aspiration and sonorant consonant devoicing are thus the result of the wide-open state of the glottis at the point of release of an onset voiceless stop in English. In Dutch neither aspiration nor sonorant consonant devoicing occur, as the opening of the glottis at the point of release of a voiceless stop is smaller in Dutch than in English. Collins and Mees (1999: 170) illustrate the difference between English and Dutch by means of the following words:

$\begin{array}{lll}\text { English: plan [plæn] } & - & \text { Dutch: plan [plan] } \\ \text { English: class [kla:s] } & - & \text { Dutch: klas [klas] }\end{array}$

Whereas the / 1 / following the initial voiceless plosive in the onset is realized as devoiced [1] in English, no devoicing occurs in Dutch.

The analysis of single word-initial voiceless stops showed that the informants considerably delayed the VOTs of English stops in comparison to Dutch stops, especially in the word-reading task. In order to find out whether they devoiced sonorant consonants following onset voiceless stops, VOTs in five Dutch and five English words in the reading task were measured. The Dutch words were trui 'jumper', klok 'clock', kreeft 'lobster', plek 'place' and pruim 'plum'; the English words were try, clean, crew, play and pray. Figure 2 shows the average VOT in the Dutch and English words per informant. The informants are presented in the same order as in Figure 1 on aspiration.

Although there are again interspeaker differences, it is clear that for all informants the average VOT in the Dutch words was considerably lower than in the English words. The average VOT in voiceless stop + sonorant consonant clusters for all informants together was $36 \mathrm{~ms}$ in the Dutch words and $93 \mathrm{~ms}$ in the English words. This latter value lies very close to the average VOT produced by the L1 English informants 




Figure 2 Sonorant consonant devoing in the Dutch (light bar) and English (dark bar) isolated word

in the English words, which was $97 \mathrm{~ms}$. In studies by Klatt (1975) and Docherty (1992) the average VOT after onset voiceless stops followed by an onset sonorant consonant was slightly lower, respectively 75 and $74 \mathrm{~ms}$. This difference might again be due to the fact that, whereas the words in these two earlier studies were embedded in carrier phrases, they occurred in isolation in the present study.

\section{Discussion}

1 Acquiring a new L2 contrast: the role of acoustic salience, perceptual cues and training

The results of the analysis of prevoicing, RVA, aspiration and sonorant consonant devoicing revealed that the Dutch-speaking learners of English did not succeed in learning the English voice contrast, as they did not acquire the short-lag stops in English.

The analysis of word-initial voiced stops in the word-reading task showed that the Dutch-speaking informants produced prevoicing in 93\% of the English tokens. While there is variation in the production of prevoicing in English (see Section III.1a), the fact that the Dutchspeaking informants produced $97 \%$ of the English tokens with prevoicing, while the English-speaking informants in this study prevoiced only $27 \%$ of the tokens indicate that the native speakers of Dutch transferred the realization of voiced stops from their mother tongue into English and 
did not succeed in acquiring English short-lag stops. This assumption was confirmed by the finding that the Dutch-speaking informants very frequently produced RVA in the direction of voicedness in English, in which it does not occur. It should be noted that, whereas prevoicing of onset stops is a phonetic implementation, RVA is a phonological rule of Dutch. The informants realized nearly all voiced stops with prevoicing in English, but produced RVA less frequently in Eng $_{\text {Dutch }}$ (59\% of the tokens) than in Dutch (92\%). This seems to indicate that learners are to some extent able to learn not to transfer phonological processes, but fail to suppress basic phonetic implementations. Further research would be needed to reveal whether L2 learners indeed manage to suppress phonological rules even when the segments involved are able to trigger the rules, because they are realized in a way that does not conform to the $\mathrm{L} 2$.

We then turn to the long-lag stops in English. In order to examine whether the informants have acquired the realization of long-lag stops in English, VOTs in single onset voiceless stops and in voiceless stops followed by a sonorant consonant were measured. The analysis of aspiration in onset stops followed by a vowel and of sonorant consonant devoicing after onset voiceless stops in the word-reading task revealed that the Dutch-speaking informants produced significantly longer VOTs in the English words than in the Dutch words.

In sum, the results suggest that, while the informants produced aspiration and sonorant consonant devoicing after onset voiceless stops, they did not acquire the complete English contrast between unaspirated short-lag stops and aspirated long-lag ones, as they did not produce the short-lag stop category in word-initial position. At the outset of this article two hypotheses were formulated about the acquisition of the voice contrast of an aspirating language by native speakers of a voicing language. The hypotheses were based on results from L1 acquisition research.

The first hypothesis was that native speakers of a voicing language will succeed in producing short-lag stops in the target aspirating language. The hypothesis was based on the assumption that short-lag stops are unmarked - because they emerge very early in first language acquisition - and on the fact that both Dutch and English have a category of short-lag stops (which in Dutch represent phonologically 'voiceless' stops and in English phonologically 'voiced' stops). However, the analysis revealed that the informants produced prevoiced instead of 
short-lag stops in English, and the hypothesis was thus not confirmed by the data. Whereas prevoicing is also possible in the speech of some native speakers of English, the informants frequently produced RVA with voiced stops as triggers, which is a phonological process of Dutch, but not of English.

The second hypothesis was that advanced learners of an aspirating language with a voicing language as their native language will succeed in producing the voiceless stops in the target language with a long-lag VOT, as aspiration is an acoustically salient phonetic implementation. This hypothesis was confirmed by the results of the present study. The informants produced native-like VOTs in onset voiceless stops followed by a vowel or a sonorant consonant. The VOTs in single onset consonants were much lower in the conversations than in the wordreading task, presumably because the phonetic implementation of aspiration sometimes fails when the informants pay minimal attention to pronunciation.

There are a number of explanations for the finding that the informants acquired the production of a long voice lag after onset voiceless stops, but did not learn to omit prevoicing and RVA.

First, whereas the acoustic salience of aspiration was considered to have a positive effect on the acquisition of long-lag stops in English, the lack of acoustic salience of prevoicing may inhibit the acquisition of short-lag stops in English. The greater acoustic salience of long-lag stops compared to short-lag ones was shown by, for instance, Pater (2003), who found that native speakers of English performed better on the discrimination of aspiration contrasts than on the discrimination of voice contrasts in Thai. Since prevoicing is acoustically non-salient, speakers who produce prevoicing in their native language might not easily perceive the difference between their own prevoiced stops and the L2 short-lag stops and may therefore be unaware of their own deviant L2 pronunciation.

Second, prevoicing is an important perceptual cue to the listener about the voice character of voiced stops in Dutch, and L1 Dutch speakers may thus be hesitant to omit this cue. Van Alphen (2004) examined the perception of prevoicing by native speakers of Dutch and showed that, when native speakers of Dutch were asked to identify (Dutch) tokens as voiced or voiceless, they frequently misjudged voiced tokens lacking prevoicing as voiceless ones. This means that for native speakers of Dutch prevoicing functions as a strong cue for the recognition of voiced 
stops. Whereas native speakers of Dutch distinguish voiced stops from voiceless ones by the presence of prevoicing in the former ones, for native speakers of English the most important cue is the occurrence of aspiration in voiceless stops and the lack of aspiration in voiced ones. Although the informants usually produce voiceless stops in English with a long-lag VOT, they produce much shorter VOTs in casual running speech when they are paying minimal attention to pronunciation. If the informants were to omit prevoicing, they would run the risk of losing the contrast between voiced and voiceless stops altogether. If informants who fail to produce aspirations, were to omit prevoicing, the two categories would overlap and the distinction between voiced and voiceless stops would become hard to perceive. Whether such an overlap would necessarily be problematic for communication is another question. In Van Alphen's (2004) data on the production of prevoicing in Dutch spoken by native speakers of Dutch from the Netherlands, $25 \%$ of all word-initial voiced stops also lacked prevoicing. Since voiceless stops are unaspirated in Dutch, there was - for these speakers - no VOT contrast between voiced and voiceless stops, although closure duration and burst intensity might still differ for voiced and voiceless stops and function as cues for the listener. It should also be noted that a voiceless stop which occurs in word-medial position as the onset of an unstressed syllable (as in, for instance, rapid) is only lightly aspirated in English, and L1 Dutch speakers may therefore categorize these stops as (Dutch) short-lag stops. This would mean that the informants consider stops realized in the short-lag region to be representative of the voiceless category. This helps explain why the learners are unlikely to produce English voiced stops without prevoicing, i.e. in the short-lag region. Moreover, both in Dutch and English, word-medial voiced stops (e.g. Dutch ober 'waiter', English rabbit) are realized as fully voiced. Native speakers of Dutch are thus hesitant to realize the English voiced stop category (/b, d, g/) in the short-lag region in word-initial position, as this is the region where they realize the voiceless stop category $(/ \mathrm{p}, \mathrm{t}, \mathrm{k} /)$ in word-medial position preceding an unstressed syllable.

A final factor that might explain why the informants had acquired the production of a voicing lag after voiceless stops - but had not learned to omit prevoicing in English word-initial stops - is that the informants had received training on the production of aspiration in pronunciation sessions, but had not been trained to produce English voiced stops without prevoicing. (All informants were students of English at university and had taken a pronunciation class in English, as described 
in Section II.) Although in most studies reporting on the positive effect of both perception and production training on learners' pronunciation the testing part follows immediately or only a short time after the training session and the informants are trained on one particular pronunciation feature only (on the effect of training the English / $\mathrm{r} /-/ \mathrm{l} /$ contrast to L1 Japanese speakers, see, for example, Yamada, 1993; Bradlow et al., 1997), it is likely that a semester-long pronunciation class in the year preceding the recordings, in which aspiration was one of the features dealt with, still had an important effect on the learners' pronunciation.

In Section I, three possible learning paths were described; these are briefly repeated here:

- Learning path 1: Native speakers of Dutch equate English short-lag stops with Dutch short-lag stops, because they are acoustically very close to one another. They may additionally learn to produce aspiration in English, as aspiration is acoustically salient.

- Learning path 2: Native speakers of Dutch fully acquire the English voice contrast, i.e. they learn that Dutch short-lag /p, t, k/ are realized with a long-lag VOT in English and that Dutch prevoiced /b, d/ are produced in the short-lag region in English.

- Learning path 3: Dutch-speaking learners of English fully transfer the Dutch realization of the contrast into English, i.e. they categorize English long-lag stops as Dutch short-lag ones and English short-lag stops as Dutch prevoiced ones.

The analysis revealed that the informants in fact followed part of learning path 1 or 2, in that they acquired the articulatory realization of longlag voiceless stops in English, and part of learning path 3, as they did not succeed in acquiring word-initial short-lag stops in English, but transferred their L1 prevoiced stops into English. The following section discusses how this pattern can be explained in terms of laryngeal features.

\section{Analysis of the results in terms of laryngeal features}

In Section I, it was mentioned that there are two approaches to the laryngeal features in Dutch and English. According to one approach, the contrast between voiced and voiceless stops in Dutch is one of [voice] and the contrast in English is one of [spread glottis]. According to the second approach the feature [voice] is the contrastive feature in both Dutch and English and the differences between these two languages in 
terms of the voice contrast are purely phonetic. Kager et al. (2007) have termed these two approaches the 'Multiple Feature Hypothesis' and the 'Single Feature Hypothesis', respectively. While the results have shown that the voice contrast in the English speech of the L1 Dutch speakers is one between prevoiced and long-lag stops, this section briefly discusses what the results tell us about the laryngeal features in Eng $_{\text {Dutch }}$ according to the Single and the Multiple Feature Hypotheses.

Proponents of both theories would agree that voiced stops in Eng $g_{\text {Dutch }}$ are specified for [voice], not only because they were produced with prevoicing in over $90 \%$ of the tokens, but also because they frequently triggered RVA in a preceding word-final obstruent in the spontaneous conversations. If RVA is considered to be a phonological process through which [voice] spreads from an onset stop to a preceding coda

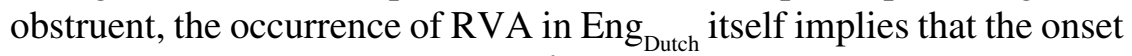
stop must be specified for [voice]. ${ }^{6}$

While the production of prevoicing and especially the occurrence of the phonological process of RVA in the English speech of the Dutch-speaking informants is a clear indication of the [voice] specification of voiced stops in Eng $_{\text {Dutch }}$, the laryngeal specification of voiceless stops in Eng Dutch $_{\text {is }}$ is hard to pin down. Both aspiration and sonorant consonant devoicing after onset voiceless stops are effects of phonetic implementation and thus cannot provide direct evidence for the phonological specification of voiceless stops in Eng ${ }_{\text {Dutch }}$. While the production of a long lag after onset voiceless stops could indicate that learners have acquired the feature [spread glottis] which is the contrastive feature in English according to the Multiple Feature Hypothesis, it could also mean that the L1 Dutch speakers have learnt a new articulatory realization in which they produce [-voice] stops with aspiration.

If the informants have indeed acquired the phonological feature [spread glottis], this would provide counterevidence to Brown's (1998) claim that it is not possible for L2 learners to acquire a feature that is not contrastive in their mother tongue. Brown bases this claim on the

${ }^{6}$ I adopt the autosegmental approach (Goldsmith, 1976), which views voice assimilations as phonological processes involving the spreading of a feature. Whereas other frameworks, in particular articulatory phonology (Browman and Goldstein, 1992), consider assimilations to be phonetic processes involving gestural overlap, I argue that RVA in Dutch is a phonological rule, which needs to be acquired and is not an automatic consequence of the [voice] specification of voiced stops in Dutch (for evidence from Swedish, see Ringen and Helgason, 2004). 
results of experiments testing the acquisition of the English contrast between $/ 1 /$ and $/ \mathrm{r} /$ by native speakers of Japanese and Chinese. Whereas the feature [coronal] - which distinguishes /l/ from / $\mathrm{r} /$ in English - is present in the phonology of (Mandarin) Chinese (though in other contexts), it is not a distinguishing feature in Japanese. The experiments showed that, whereas native speakers of Chinese succeeded in perceiving the contrast between $/ 1 /$ and $/ \mathrm{r} /$ in a native-like way, the Japanese speakers did not accurately discriminate or phonologically perceive the contrast.

One reason for the finding that the Dutch learners of English could acquire the feature [spread glottis] might be that it is contrastive elsewhere in Dutch (in which case the Dutch-speaking learners should be compared to the Chinese rather than to the Japanese subjects learning the contrast between English /r/ and /1/). Iverson and Salmons (2003) suggest that the feature [spread glottis] might actually be active in Dutch, though in fricatives rather than in stops. They argue that the Dutch fricative system is a laryngeally mixed system, in which voiced fricatives are marked for [voice] and voiceless fricatives are marked for [spread glottis]. They base this proposal on Vaux's (1998) claim that it is unmarked for voiceless fricatives to be specified for [spread glottis]. Iverson and Salmons elaborate on this idea (first formulated as Vaux's Law by Avery and Idsardi, 2001) and claim that fricatives that are unspecified become specified for [spread glottis] in a system in which [spread glottis] is not contrastive. Since voiced fricatives are specified for [voice] in Dutch (and the contrast is thus not one of [spread glottis]), the unspecified voiceless fricatives become marked for [spread glottis]. If voiceless fricatives are indeed marked for [spread glottis] in Dutch, it would make the task for the Dutch learners of English much easier, as they would only have to extend this feature to a new segment type, namely the voiceless stops in English. One argument against the [spread glottis] specification of voiceless fricatives in Dutch is, however, that sonorant consonants do not devoice after onset voiceless stops or fricatives (as in flink [flınk] 'good, sweet' and sla [sla:] 'lettuce'). Although the delay in VOT is definitely greater when the sonorant consonant follows a stop than when it follows a fricative in English, some sonorant devoicing can be heard in words like flat and slip (Collins and Mees, 1999: 169). If sonorant consonant devoicing is the phonetic implementation of the phonological representation of [spread glottis] in onset voiceless fricatives, the absence of it in Dutch would indicate that voiceless fricatives are not marked for [spread glottis], as in English. 
An alternative reason why the Dutch learners were able to acquire the feature [spread glottis] in English is that the task for native speakers of Japanese learning the English contrast between /r/ and /1/ is different from that of native speakers of Dutch learning the English contrast between voiceless and voiced stops. Since Japanese has only one liquid phoneme /r/, while English has a contrast between /r/ and /l/, L1 Japanese speakers have to create a new category when learning English. L1 Dutch speakers, on the other hand, have to map a two-way contrast between voiced and voiceless segments onto a new two-way contrast in the target language. This is illustrated in Figure 3.

Thus, although in both cases learners have to acquire a new phonological feature, the Dutch-speaking learners of English have to replace a feature [voice], which marks the contrast between voiced and voiceless stops in their L1, by a new feature [spread glottis], while the Japanese learners have to acquire a new feature [coronal] to make a contrast which does not correspond to a two-way contrast in their L1.

While it is thus possible that voiceless stops in Eng $_{\text {Dutch }}$ are specified for [spread glottis], it is hard to provide evidence for the phonological specification of voiceless stops in $\mathrm{Eng}_{\text {Dutch }}$, since aspiration in not an active phonological process, but a phonetic phenomenon. If voiceless stops in Eng $_{\text {Dutch }}$ are considered to be specified for [spread glottis], the production of aspiration is an automatic consequence of the phonological specification (under the Multiple Feature Hypothesis). If they are specified for [-voice] (in a binary Single Feature Hypothesis), the production of aspiration is the result of the learners' realization that voiceless stops in English are phonetically realized with a

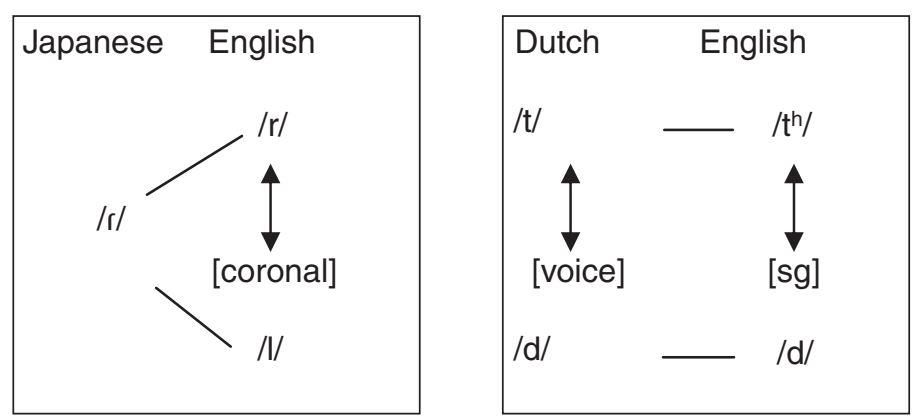

Figure 3 Acquisition of new phonological features in $\mathrm{Eng}_{\mathrm{Jap}}$ and $\mathrm{Eng}_{\text {Dutch }}$ 
voicing lag. ${ }^{7}$ However, more important than the laryngeal specification of voiceless stops for this study is the finding that the voiced stop category in Eng ${ }_{\text {Dutch }}$ is phonologically specified for [voice], realized with prevoicing in word-initial position and that it functions as a trigger of the phonological process of RVA.

\section{Comparison with L1 acquisition}

The results of the study lead to questions with respect to the similarity of first versus second language acquisition of laryngeal systems. Two points of interest are discussed here.

First, as was mentioned in Section I, Kager et al. (2007) on the acquisition of laryngeal features found that children learning their mother tongue show a preference for short-lag stops. Children learning an aspirating language such as English tend to produce short-lag stops instead of long-lag ones, and children learning a voicing language such as Dutch are reported to produce short-lag stops instead of prevoiced ones. The results in the present article suggest that the laryngeal system in Eng ${ }_{\text {Dutch }}$ lacks exactly this category that is favoured in child speech: learners did not produce onset short-lag stops in word-initial position. Instead, they produced one category with prevoicing (as in Dutch) and the other category with long-lag VOT (as in English). This means that the drive towards unmarked, short-lag stops, which is strong in L1 acquisition, is overruled in L2 acquisition by the learners' tendency to transfer prevoiced stops from their L1 into the L2. The production of prevoicing is aerodynamically difficult (see Section III.1a) and acquired late in L1 acquisition. Macken and Barton (1980), for instance, found that children learning Spanish as their mother tongue had not learned to produce prevoicing by the age of $3 ; 10$ (although they note

${ }^{7}$ In order to examine whether the informants had just acquired one single articulatory pattern in English - i.e. the realization of onset voiceless stops - or whether they had also acquired other aspects of the English laryngeal system, an analysis of pre-consonantal vowel length was carried out. While vowel length does not vary with the underlying voice specification of the final stop in Dutch, in English vowels are significantly shorter before final voiceless stops than before voiced ones (see, for example, Cruttenden, 2001: 96). The word-reading task contained three minimal pairs differing only in the voice character of the final stop, namely bet-bed, bit-bid and bite-bide. The analysis of vowel length revealed that the vowels produced by the Dutch-speaking informants were $50 \%$ longer before final voiced stops than before voiceless ones. While the analysis of pre-consonantal vowel length does not provide evidence for either the Single or the Multiple Feature Hypothesis, it does show that the informants have not just acquired the articulatory pattern of voiceless stops in onset position, but have also learnt other acoustic cues of the laryngeal contrast of the target language. 
that this late age of acquisition might also be the result of a Spanish rule of allophonic distribution of the voiced stops $[\mathrm{b}, \mathrm{d}, \mathrm{g}]$ and the spirants $[\beta, \delta, \gamma])$. Studies on bilingual acquisition of an aspirating and a voicing language are in line with this observation: the voice contrast of the aspirating language is normally acquired before the one in the voicing language, where the production of prevoicing usually forms the problem (on Spanish-English, see Deuchar and Clark, 1996; on JapaneseEnglish, see Johnson and Wilson 2002; on Spanish-German bilingual acquisition, see Kehoe et al., 2004).

The results from the present study showed that, while prevoicing is acquired late in L1 (monolingual and bilingual) acquisition, once it is acquired it is very difficult to get rid of it in L2 acquisition of a language which has a short-lag-long-lag rather than a voicing-lead-short-lag contrast.

A second point of comparison between the L1 and L2 acquisition of laryngeal features is of a typological nature. Many experimental studies on L1 acquisition have shown that children have access to certain aspects of Universal Grammar (UG) during the acquisition process, as the child's developing grammar shows properties which the child could not have derived from the input only (see Crain and Fodor, 1993). As White (1989: 51) points out, a question related to the influence of UG on the acquisition process is whether developing grammars violate principles of UG. In L1 acquisition research it has been proposed that developing grammars do indeed follow UG principles and that every grammar that occurs at some stage in the acquisition process corresponds to the grammar of a possible natural language (Pinker, 1984). Levelt and Van de Vijver (2004), for instance, investigated the correspondence between syllable types in natural languages and the developmental paths followed in L1 acquisition. They found that their data largely confirmed this correspondence, though there was no perfect 1:1 relation. The proposal that developing grammars must correspond to grammars of natural languages - sometimes referred to as the Strong Continuity Hypothesis (Lust, 1999) - has also been investigated in the context of L2 acquisition (see, for example, White, 1989). If the continuity hypothesis holds for second language acquisition too, this would mean that, in the case at hand, the laryngeal system of Eng ${ }_{\text {Dutch }}$, in which onset voiceless stops are aspirated and onset voiced stops are consistently prevoiced, is a possible laryngeal system of a natural language. How frequent natural languages are which have a contrast between prevoiced and voiceless aspirated stops (and only between these, i.e. languages which have a three-way 
or four-way contrast excluded) is unclear. In the UPSID database, ${ }^{8}$ only 7 out of 451 languages contrast voiced with voiceless aspirated stops. Keating et al. (1983), however, compiled a database with phonetic detail for 51 languages. Of these 51 languages 29 have a two-way contrast, 14 of which seem to contrast prevoiced stops with long-lag voiceless stops in initial position. Since the smaller sample in Keating et al.'s study contains more phonetic detail and is thus more accurate, languages contrasting voiced with voiceless aspirated stops might not be as exceptional as the UPSID database suggests. However, these results need to be treated with caution, as the majority of languages in Keating et al.'s sample are European, which might have an influence on the results. Moreover, for some languages (like English) there are different possibilities: whereas some speakers have a voicing-lead-long-lag contrast, others have a short-lag-long-lag contrast. The frequency with which different patterns occur in a particular language is unclear.

\section{Conclusions and suggestions for further research}

This study has examined the acquisition of the voice contrast in an aspirating language, English, by native speakers of a voicing language, Dutch. The analysis of the production of prevoicing, RVA, aspiration and sonorant consonant devoicing after onset voiceless stops revealed that the voice system in Eng $_{\text {Dutch }}$ shows an interesting pattern: it contrasts prevoiced stops, which occur in Dutch but not in English, with long-lag ones, which occur in English but not in Dutch. This means that the learners did not succeed in acquiring the short-lag stop category of the aspirating language, despite the fact that they have a category of short-lag stops in their L1. Various explanations for the fact that the learners acquired the long-lag stops but not the short-lag ones were considered.

First, while aspiration after onset voiceless stops is acoustically salient, the production of prevoicing in the learners' L1 is not. As a result, advanced L1 Dutch learners of English notice that aspiration is a property of voiceless stops in the target language and will aim at producing a voicing lag after onset voiceless stops; however, they do not notice that the target voiced stops (i.e. the short-lag ones) are different from their L1 prevoiced stops and hence they are likely to transfer prevoiced

${ }^{8}$ The UCLA Phonological Segment Inventory Database (UPSID) was developed by Maddieson at the University of California, Los Angeles, CA (and is presented in Maddieson, 1984). 
stops into English. The analysis of the conversational speech revealed that these prevoiced stops also frequently triggered RVA, which does not normally occur in English.

Second, earlier research by Van Alphen (2004) has shown that prevoicing is a strong perceptual cue to the voice category of stops in Dutch. This explains why L1 Dutch-speaking learners of English - who have a long-time habit of producing initial stops with prevoicing - are hesitant to 'lose' this perceptual marker of the voice category.

Finally, in a pronunciation course preceding the collection of the data for this study, the learners received explicit instruction on the production of aspiration in English voiceless stops, but not on the absence of prevoicing in (phonologically) voiced stops.

The analysis thus illustrated that factors such as acoustic salience, perceptual cues and training shape the acquisition of a new L2 contrast and should be taken into account when analysing L2 systems.

The results were also analysed in terms of laryngeal feature theories. It was shown that, whereas voiced stops in Eng ${ }_{\text {Dutch }}$ are clearly specified for [voice] - as they are phonetically produced with prevoicing and function as triggers of RVA - it is hard to pin down the laryngeal specification of voiceless stops in the learners' L2. While the production of a voicing lag after onset voiceless stops could be the phonetic implementation of a [spread glottis] specification in an approach in which the feature [voice] is contrastive in voicing languages and the feature [spread glottis] in aspirating languages, it could also be the result of the learners' acquisition of a new articulatory realization, i.e. the production of English [-voice] stops in the long-lag VOT region. While the study did not provide exclusive evidence for either a [spread glottis] or a [-voice] specification of voiceless stops in $\mathrm{Eng}_{\text {Dutch }}$, it did show that the L1 Dutch speakers did not acquire short-lag stops in English; in this way the L2 acquisition of a laryngeal contrast is strikingly different from L1 acquisition.

While children acquiring a voicing language as well as children acquiring an aspirating language go through a first stage in which they produce all stops in the short-lag region, the adult L1 speakers of a voicing language acquiring an aspirating language produce prevoicing and long-lag stops, but lack the target short-lag category. While the tendency to produce unmarked short-lag stops is important in first language acquisition, in second language acquisition this drive towards unmarked structures is overridden by the pressure to keep the perceptual cue of voiced stops in the L1, namely prevoicing, intact in the L2. A similarity between first 
and second language acquisition was that aspirated long-lag stops are acquired relatively easily. An interesting topic for further research would be the perception of English short-lag and long-lag stops by early learners of English who did not receive training on the production of aspiration. A categorization task in which learners are asked to categorize English short-lag and long-lag stops would help us to tease apart the influence of explicit instruction and acoustic salience of the target property in the L2 acquisition of a new laryngeal contrast.

\section{Acknowledgements}

The research reported on in this work was carried out at the English Department of Ghent University and was made possible through a doctoral grant from the Fund for Scientific Research - Flanders (FWO) (2002-06). When the results were written up the author was a visiting post-doctoral scholar at the Linguistics Department of the University of Massachusetts, Amherst, MA (2006-07), sponsored by a grant from the Francqui Foundation / Belgian American Educational Foundation (BAEF). The author thanks Mieke Van Herreweghe, Beverley Collins and Joe Pater for discussions on earlier versions of this study, Paula Fikkert and three anonymous Second Language Research reviewers for many helpful comments and suggestions, and all informants for their participation.

\section{References}

Avery, P. and Idsardi, W.J. 2001: Laryngeal dimensions, completion and enhancement. In Hall, T.A., editor, Distinctive feature theory. Berlin: Mouton de Gruyter, 41-70.

Best, C.T. 1994: The emergence of native-language phonological influences in infants: a perceptual assimilation hypothesis. In Goodman, J.C. and Nusbaum, H.C., editors, The development of speech perception. Cambridge, MA: MIT Press, 167-224.

— 1995: A direct realist perspective on cross-language speech perception. In Strange, W., editor, Speech perception and linguistic experience: theoretical and methodological issues in cross-language speech research. Timonium, MD: York Press.

Best, C.T., McRoberts, G.W. and Goodell, E. 2001: Discrimination of nonnative consonant contrasts varying in perceptual assimilation to the listener's native phonological system. Journal of the Acoustical Society of America 109, 775-94. 
Boersma, P. and Weenink, D. 2008: Praat: doing phonetics by computer. [Computer program.] Available online at http://www.praat.org (April 2009).

Booij, G. 1995: The phonology of Dutch. Oxford: Clarendon Press.

Bradlow, A.R., Pisoni, D.B., Akahane-Yamada, R. and Tohkura, Y. 1997: Training Japanese listeners to identify /r/ and /1/; IV: Some effects of perceptual learning on speech production. Journal of the Acoustical Society of America 101, 2299-2310.

Browman, C. and Goldstein, L. 1992: Articulatory phonology: an overview. Phonetica 49, 155-80.

Brown, C. 1998: The role of the L1 grammar in the L2 acquisition of segmental structure, Second Language Research 14, 136-93.

Cho, Y.M.Y. 1999: Parameters of consonantal assimilation. Studies in Theoretical Linguistics 15. Munich: Lincom Europa.

Collier, R. and Droste, F.G. 1983: Fonetiek en fonologie [Phonetics and phonology]. Leuven: Acco.

Collins, B. and Mees, I.M. 1999: The phonetics of English and Dutch. Leiden: Brill.

Crain, S. and Fodor, J.D. 1993: Competence and performance in child language. In Dromi, E., editor, Language and cognition: a developmental perspective. Norwood, NJ: Ablex, 141-71.

Cruttenden, A., editor, 2001: Gimson's pronunciation of English. 6th edition. London: Arnold. Originally published as A.C. Gimson 1962: An introduction to the pronunciation of English.

Darcy, I. 2006: Assimilation phonologique et reconnaissance des mots. [Phonological assimilation and word recognition]. Bern/Berlin: Peter Lang.

Deuchar, M. and Clark, A. 1996: Early bilingual acquisition of the voicing contrast in English and Spanish. Journal of Phonetics 24, 351-65.

Docherty, G.J. 1992: The timing of voicing in British English obstruents. Berlin/New York: Foris.

Eggen, T.J.H.M. and Sanders, P.F., editors, 1993: Psychometrie in de praktijk [Psychometry in practice]. Arnhem: Cito.

Escudero, P. 2005: Linguistic perception and second language acquisition: explaining the attainment of optimal phonological categorization. $\mathrm{PhD}$ thesis, Utrecht University. LOT Dissertation Series 113.

Fikkert, P. 1994: On the acquisition of prosodic structure. $\mathrm{PhD}$ thesis, Leiden University. HIL Dissertation Series 6. The Hague: Holland Academic Graphics.

Flege, J.E. 1982: The voicing contrast between English /p/ and /b/ as a function of stress and position-in-utterance. Journal of Phonetics 10, 335-45.

Flege, J.E. and Eeftink, W. 1987: Cross-language switching in stop consonant perception and production by Dutch speakers of English. Speech Communication 6, 185-202. 
Goldsmith, J.A. 1976: Autosegmental phonology. $\mathrm{PhD}$ thesis. Indiana University Linguistics Club. New York: Garland.

Honeybone, P. 2005: Diachronic evidence in segmental phonology: the case of laryngeal specifications. In Van Oostendorp, M. and Van de Weijer, J., editors, The internal organization of phonological segments. Berlin: Mouton de Gruyter, 319-54.

Ito, Ch., Kang, Y. and Kenstowicz, M. 2006: The adaptation of Japanese loan words into Korean. MIT Working Papers in Linguistics 52, 65-104.

Iverson, G. and Salmons, J. 1995: Aspiration and laryngeal representation in Germanic. Phonology 12, 369-96.

- 1999: Glottal spreading bias in Germanic. Linguistische Berichte 178, 135-51.

_ 2003: Legacy specification in the laryngeal phonology of Dutch. Journal of Germanic Linguistics 15, 1-26.

— 2006: On the typology of final laryngeal neutralization: evolutionary phonology and laryngeal realism. Theoretical Linguistics 32, 205-16.

Jansen, W. 2004: Laryngeal contrast and phonetic voicing: a laboratory phonology approach to English, Hungarian, and Dutch. $\mathrm{PhD}$ thesis. Groningen: Groningen Dissertation in Linguistics.

Johnson, C.E. and Wilson, I.L. 2002: Phonetic evidence for early language differentiation: research issues and some preliminary data. International Journal of Bilingualism 6, 271-89.

Jones, M.J. and McDougall, K. 2005: An acoustic study of fricated realisations of / $\mathrm{t} /$ in Australian English. Unpublished paper presented at the 5th UK Language Variation and Change Conference, September.

Kager, R., Van der Feest, S., Fikkert, P., Kerkhoff, A. and Zamuner, T. 2007: Representations of [voice]: evidence from acquisition. In Van der Torre, E.J. and Van de Weijer, J., editors, Voicing in Dutch. Amsterdam: Benjamins, 41-80.

Keating, P., Lisker, W. and Huffman, M. 1983: Patterns in allophone distribution for voiced and voiceless stops. Journal of Phonetics 11, 277-90.

Kehoe, M.M., Lleó, C. and Rakow, M. 2004: Voice onset time in bilingual German-Spanish children. Bilingualism: Language and Cognition 7, 71-88.

Kessinger, R.H. and Blumstein, S.E. 1998: Effects of speaking rate on voiceonset time and vowel production: some implications for perception studies. Journal of Phonetics 26, 117-28.

Kim, H.K. and Zsiga, E.C. 2002: Assimilation and neutralization in Korean English interlanguage. Unpublished abstract from the 8th Conference on Laboratory Phonology 2002, Yale University and Haskins Laboratories, New Haven, CT. 
Kingston, J. 2004: Phonetics for Linguists. Unpublished course book, University of Massachusetts, Amherst, MA.

Kingston, J. and Diehl, R.L. 1994: Phonetic knowledge, Language 70, 419-54.

Klatt, D.H. 1975: Voice onset time, frication, and aspiration in word-initial consonant clusters. Journal of Speech and Hearing Research 18, 686-706.

Kuijpers, C.T.L. 1993: Temporal coordination in speech development: a study on voicing contrast and assimilation of voice. Unpublished $\mathrm{PhD}$ thesis, University of Amsterdam.

Levelt, C.C. 1994: On the acquisition of place of articulation. $\mathrm{PhD}$. Thesis, Leiden University. HIL Dissertation Series 8.

Levelt, C.C. and Van de Vijver, R. 2004: Syllable types in cross-linguistic and developmental grammars. In Kager, R., Pater, J. and Zonneveld, W., editors, Constraints in phonological acquisition. Cambridge: Cambridge University Press, 204-18.

Lisker, L. and Abramson, A.S. 1964: A cross-language study of voicing in initial stops: acoustical measurements. Word 20, 384-422.

Lombardi, L. 1995: Laryngeal features and privativity. Linguistic Review 12, 35-59.

- 1996: Postlexical rules and the status of privative features. Phonology 13, 1-38.

Lust, B. 1999: Universal Grammar: the strong continuity hypothesis in first language acquisition. In Ritchie, W.C. and Bhatia, T.K., editors, Handbook of child language acquisition. San Diego, CA: Academic Press, $111-55$.

MacWhinney, B. 1999: The Childes system. In Ritchie, W.C. and Bhatia, T.K., editors, Handbook of child language acquisition. London: Academia Press, 475-94.

Macken, M.A. and Barton, D. 1979: The acquisition of the voicing contrast in English: a study of voice onset time in word-initial stop consonants. Journal of Child Language 7, 41-74.

— 1980: The acquisition of the voicing contrast in Spanish: a phonetic and phonological study of word-initial stop consonants. Journal of Child Language 7, 433-58.

Maddieson, I. 1984: Patterns of sounds. Cambridge: Cambridge University Press.

Pater, J. 2003: The perceptual acquisition of Thai phonology by English speakers: task and stimulus effects. Second Language Research 19, 209-23.

Pinker, S. 1984: Language learnability and language development. Cambridge MA: Harvard University Press.

Ringen, C.O. and Helgason, P. 2004: Distinctive [voice] does not imply regressive assimilation: evidence from Swedish, International Journal of English Studies 4, 53-71. 
Slis, I.H. 1985: The voiced-voiceless distinction and assimilation of voice in Dutch. Helmond: Wibro.

Snow, D. 1997: Children's acquisition of speech timing in English: a comparative study of voice onset time and final syllable vowel lengthening. Journal of Child Language 24, 35-56.

Spencer, A. 1996: Phonology: theory and description. Cambridge, MA: Blackwell.

Trommelen, M. and Zonneveld, W. 1979: Inleiding in de generatieve fonologie [Introduction to generative phonology]. Muidenberg: Coutinho.

Van Alphen, P.M. 2004: Perceptual relevance of prevoicing in Dutch. $\mathrm{PhD}$ thesis, Radboud University, Nijmegen. MPI Series in Psycholinguistics.

Van der Feest, S. 2007. Building a phonological lexicon: the acquisition of the Dutch voicing contrast in perception and production. $\mathrm{PhD}$ thesis, Radboud University, Nijmegen. Nijmegen: Prince Productions.

Van Dommelen, W.A. 1983: Some observations on assimilation of voicing in German and Dutch. In Van den Broecke, M., Van Heuven, V. and Zonneveld, W., editors, Studies for Antonie Cohen: sound structures. Dordrecht: Foris, 47-56.

Vaux, B. 1998: The laryngeal specifications of fricatives. Linguistic Inquiry 29, 497-511.

Vaux, B. and Samuels, B. 2005: Laryngeal markedness and aspiration. Phonology 22, 395-436.

Wetzels, W.L. and Mascaró, J. 2001: The typology of voicing and devoicing. Language 77, 207-44.

White, L. 1989: Universal Grammar and second language acquisition. Amsterdam: John Benjamins.

Yamada, R.A. 1993: Effects of extended training on /r/ and /1/ identification by native speakers of Japanese. Journal of the Acoustical Society of America 93, 2391A. 
Appendix 1 A complete list of the words from the reading task

\begin{tabular}{llll}
\hline \multicolumn{2}{c}{ List of Dutch words } & \multicolumn{1}{c}{ List of English words } \\
\hline /b/_[V & /d/_[V & /b/_[V & /d/_[V \\
\hline bind ('bind') & dik ('fat') & bit & did \\
bed ('bed') & denk ('think') & bid & diet \\
beek ('stream') & deel ('part') & bite & died \\
bal ('ball') & dans ('dance') & bide & deal \\
bak ('bin') & dal ('valley') & bet & dirt \\
baan ('road/job') & dol ('crazy') & bed & date \\
bol ('ball, sphere') & dom ('stupid, dull') & bean & dance \\
bod ('bid') & doos ('box') & ball & doll \\
bot ('bone') & deuk ('dent') & bought & dot \\
boom ('tree') & duin ('dune') & boy & doom \\
\hline vcl.stop]_[V & vcl.stop[_[son.C & vcl.stop]_[V & vcl.stop]_[son.C \\
\hline paar ('pair') & plek ('spot') & pie & play \\
test ('test') & pruim ('plum') & take & pray \\
kaak ('cheek') & trui ('jumper') & cake & try \\
& klok ('clock') & & clean \\
\hline vcd.fric.]_[V & kreeft ('lobster') & & crew \\
\hline veel ('many') & & vcd.fric.]_[V & \\
zee ('sea') & & very & \\
& & zero & \\
\hline vcl.fric.]_[V & vcl.fric.]_[son.C & vcl.fric.]_[V & vcl.fric.]_[son.C. \\
\hline fout ('mistake') & fles ('bottle') & fire & fly \\
saai ('boring') & fris ('fresh') & sir & slow \\
& slag ('blow') & smile \\
\hline & smaak ('taste') & snoep ('sweets') & snack \\
& & & \\
\hline
\end{tabular}

Notes: vcl.stop = voiceless stop; son.C = sonorant consonant; vcd.fric. = voiced fricative; vcl.fric. = voiceless fricative. While words are grouped according to their onset consonant(s), in the experiment they were presented in such an order that words which started with the same consonant were not presented after each other, so as to prevent the informant's attention from being drawn to this consonant. 